\title{
An Integrated Thermal Science MATLABß Project
}

\section{Dr. Tom Eldredge, Liberty University}

Tom Eldredge received his B.S., M.S., and Ph.D. degrees all in mechanical engineering from the University of Tennessee. He is an Associate Professor of mechanical engineering at Liberty University. He is a Professional Engineer, licensed in the state of Connecticut. Tom Eldredge has over 25 years of experience in computational fluid dynamics (CFD) modeling, related to the power industry for design of combustion systems, cooling tower modeling, and hydro power applications. He has an interest in energy research, particularly as it relates to the thermal sciences and fluid mechanics.

\section{Dr. John H Jones, Liberty University}

John H. Jones received a BS in mechanical engineering with a nuclear minor from Virginia Tech and a PhD in mechanical engineering from the University of Virginia. Additionally he has several masters in mechanical and industrial/systems engineering from the two universities. He has over 40 years of experience developing thermal science computer codes and methods for a global energy provider. He is an adjunct instructor at Liberty University and is interested in bringing industrial type problems into the classroom. 


\title{
An Integrated Thermal Science MATLAB ${ }^{\circledR}$ Project
}

\begin{abstract}
Thermal science courses are typically taught as separate disciplines (thermodynamics, heat transfer, and fluid dynamics) with very little if any integration of the disciplines. Industrial applications of thermal science use all three disciplines in an integrated manner. A vertical heated pipe flow problem is used to help junior-level mechanical engineering students see that the three disciplines of thermal science are integrated and not segregated. The vertical heated pipe flow problem is a simplified version of industrial applications and requires that a programming software tool be used to generate a solution. For this application $\mathrm{MATLAB}^{\circledR}$ was used, although other platforms, such as EXCEL $^{\circledR}$, could be used.
\end{abstract}

\section{Introduction}

The heated pipe flow problem has a nonuniform axial power shape (APS), with a series of different normalized profiles assigned. The problem requires the generation of axial temperatures, enthalpies, coolant velocities, pressure drops, pipe inner wall surface temperatures, and safety factors. The working fluid for the pipe flow problem is water. All of the thermal properties used in generating the required axial profiles are determined using an equation of state (EOS). MATLAB ${ }^{\circledR}$ is used to generate the required axial profiles. In addition to the MATLAB ${ }^{\circledR}$-based results, a technical report summarizing the system of equations, results, and evaluation of the safety of the operating conditions is a required deliverable.

The problem formulation is described based on the various governing equations from thermal science textbooks and an open-literature critical heat flux (CHF) correlation, which is used to provide a safety factor. The problem formulation is followed by a list of the assumptions used in the problem. The problem specific inputs are contained in the next section, which is followed by the results. A pre- and post-project learning assessment was performed to determine if the students' understanding of integrated thermal science improved as a result of the project. The Appendix contains the learning assessment provided to the students.

The Nomenclature section describes all of the variables used in this paper.

\section{Problem Formulation}

The first law of thermodynamics is required to generate an axial enthalpy profile based on inlet boundary conditions (inlet flow and temperature), a nonuniform axial power shape, and a specified operating pressure. The first law is defined as follows ${ }^{1}$ :

$$
\frac{d E_{c v}}{d t}=\dot{Q}_{c v}-\dot{W}_{c v}+\sum_{i}\left\{\dot{m}_{i}\left(h_{i}+\frac{V_{i}^{2}}{2}+g z_{i}\right)\right\}-\sum_{e}\left\{\dot{m}_{e}\left(h_{e}+\frac{V_{e}^{2}}{2}+g z_{e}\right)\right\}
$$


The pressure drop is based on the equation resulting from a mechanical energy balance for an incompressible fluid ${ }^{2}$ :

$$
\left(\frac{p_{i}}{\gamma}+\frac{V_{i}^{2}}{2 g}+z_{i}\right)+h_{\text {Pump }}=\left(\frac{p_{e}}{\gamma}+\frac{V_{e}^{2}}{2 g}+z_{e}\right)+h_{\text {Turbine }}+h_{L}
$$

The major and minor heat loss term ${ }^{2}\left(h_{L}\right)$ is defined as follows:

$$
h_{L}=\left(\frac{V^{2}}{2 g}\right)\left(\frac{f L}{D}+K_{L}\right)
$$

The minor head losses (based on loss coefficient $\mathrm{K}_{\mathrm{L}}$ in Equation 3) are Reynolds Number dependent and are applied at specific axial locations along the pipe. The minor head losses only apply over a specific axial region of the pipe.

The friction factor (f) in Equation 3 is based on the Haaland friction correlation ${ }^{2}$, if the flow is turbulent; otherwise the laminar flow correlation listed below is used:

$$
\begin{aligned}
& \frac{1}{\sqrt{f}}=-1.8 \log \left(\left(\frac{\frac{\varepsilon}{D}}{3.7}\right)^{1.11}+\frac{6.9}{R e}\right) \leftarrow \text { Haaland } \\
& f=\frac{64}{\operatorname{Re}} \leftarrow \text { laminar }
\end{aligned}
$$

The pipe inner surface temperature is based on Newton's law of cooling, which is as follows ${ }^{3}$ :

$$
Q=h_{\text {conv }} A_{h t}\left(T_{\text {Wall }}-T_{\text {Fluid }}\right)
$$

The single-phase heat transfer coefficient is based on either of the following correlations ${ }^{3}$ :

$$
N u=\frac{h_{\text {conv }} D}{k}=\left\{\begin{array}{cc}
4.0 & \text { laminar } \\
0.023(R e)^{0.8}(P r)^{0.4} & \text { turbulent }
\end{array}\right\}
$$

The safety factor is based on a critical heat flux correlation defined as follows ${ }^{4}$ :

$$
\text { Safety factor }=\frac{q_{C H F}^{\prime \prime}}{F_{\text {DatL }} q^{\prime \prime}(z=L)}
$$


The uniform CHF $\left(q_{C H F}^{\prime \prime}\right)$ is defined as follows ${ }^{4}$ :

$$
q_{C H F}^{\prime \prime}=\frac{(a-b D)\left[A_{1}\left(A_{2} G\right)^{A_{3}+A_{4}(P-2000)}-A_{9} G x_{C H F} h_{f g}\right]}{A_{5}\left(A_{6} G\right)^{A_{7}+A_{8}(P-2000)}}
$$

The $\mathrm{F}_{\mathrm{D}}$ factor $\left(F_{\text {Dat }}\right)$, which is evaluated at each axial location $\mathrm{L}$ in the pipe, accounts for the nonuniform behavior of the APS and is as follows ${ }^{4}$ :

$$
\begin{aligned}
& F_{\text {Dat } L}=\frac{K_{D} C}{q^{\prime \prime}(z=L)\left(1-e^{-C L}\right)} \int_{0}^{L}\left[q^{\prime \prime}(z)\right] e^{-C(L-z)} d z \\
& C=A_{21} \frac{\left(1-x_{C H F}\right)^{A_{22}}}{\left(\frac{G}{10^{6}}\right)^{A_{23}}}
\end{aligned}
$$

The coefficients used in Equation 7 are defined in Table $1^{4}$.

The independent variables in Equations 8 and 9 have specific unit requirements. The specific unit requirements are as follows ${ }^{4}$ :

- Hydraulic diameter (D) is in inches.

- Mass flux (G) is in $\mathrm{lb}_{\mathrm{m}} /\left(\mathrm{hr}-\mathrm{ft}^{2}\right)$.

- Pressure $(\mathrm{P})$ is in psia.

- Latent heat of vaporization $\left(\mathrm{h}_{\mathrm{fg}}\right)$ is in $\mathrm{Btu} / \mathrm{lb} \mathrm{b}_{\mathrm{m}}$.

- Axial locations (z and L (fixed location)) are in inches.

- Thermodymamic quality at a specified axial location where CHF is calculated $\left(\mathrm{x}_{\mathrm{CHF}}\right)$ is defined as follows:

$$
x_{C H F}=\frac{h-h_{f}}{h_{f g}}
$$

The thermodynamics quality at CHF is different than flowing quality since the values can be negative as well as varying up to a value of 1.0, at least for the vertical pipe flow application. This definition of quality is used in the development of the CHF correlation based on the experimental data base ${ }^{4}$. 
Table 1 - Coefficients for the Equation 8 critical heat flux correlation.

\begin{tabular}{|c|c|c|c|}
\hline $\begin{array}{c}\text { Symbolic } \\
\text { coefficient }\end{array}$ & Numerical value & $\begin{array}{c}\text { Symbolic } \\
\text { coefficient }\end{array}$ & Numerical value \\
\hline \hline $\mathrm{a}$ & 1.15509 & $\mathrm{~A}_{7}$ & 0.7118615971 \\
\hline $\mathrm{b}$ & 0.40703 & $\mathrm{~A}_{8}$ & $0.207291379 \mathrm{E}-3$ \\
\hline $\mathrm{A}_{1}$ & $0.37020 \mathrm{E} 8$ & $\mathrm{~A}_{9}$ & 0.1520823945 \\
\hline $\mathrm{A}_{2}$ & $0.591365895 \mathrm{E}-6$ & $\mathrm{~A}_{21}$ & 0.2486718455 \\
\hline $\mathrm{A}_{3}$ & 0.8303988568 & $\mathrm{~A}_{22}$ & 7.822927921 \\
\hline $\mathrm{A}_{4}$ & $0.6847857197 \mathrm{E}-3$ & $\mathrm{~A}_{23}$ & 0.4575806605 \\
\hline $\mathrm{A}_{5}$ & 12.70981356 & $\mathrm{~K}_{\mathrm{D}}$ & 1.02508 \\
\hline $\mathrm{A}_{6}$ & $0.3054491127 \mathrm{E}-5$ & & \\
\hline
\end{tabular}

The safety factor adjustment that accounts for the nonuniform axial power shape requires a numerical integration; which is defined as follows for a specified axial location $\mathrm{L}^{6}$, where $\mathrm{N}$ is the control volume number of location $\mathrm{L}$ relative to the start of the vertical pipe:

$$
F_{\text {Dat } L}=K_{D}\left[\frac{e^{-C L}}{\left\{q^{\prime \prime}(z=L)\right\}\left\{1-e^{-C\left(L-z_{1}\right)}\right\}}\right]\left[\sum_{j=2}^{N}\left(\left\{q^{\prime \prime}(j)\right\}\left\{e^{C z_{j}}-e^{C z_{j-1}}\right\}\right)\right]
$$

The last equation that is required to determine the required conditions for the vertical heated pipe is an EOS, defined as follows:

$$
\phi=f(p, h)
$$

The EOS allows all the required thermal properties $(\phi)$ to be determined once the axial enthalpy profile is generated from Equation 1. The EOS is based on a MATLAB ${ }^{\circledR}$-based version of IAPWS-IF97 $7^{5}$, which was vectorized to minimize computation time.

\section{Assumptions}

The assumptions used in the vertical heated pipe flow problem are as follows:

1) Steady state.

2) Due to the nonuniform axial power shape the axial pipe length is divided into a series of equal-sized control volumes.

3) Kinetic energy and elevation effects in the first law of thermodynamics (Equation 1) may be neglected since the predominant term in the equation is the heat input to the pipe. Kinetic and potential energy are included in the mechanical energy equation (Equation 2).

4) The flow is fully developed, one dimensional, and single-phase liquid over the entire length of the pipe. 
5) The pressure drop from the inlet to exit of the pipe is small compared to the operating pressure; thus all of the water properties may be evaluated at the pipe exit pressure. For the evaluation of the safety factor this is a conservative assumption.

6) The transition from laminar to turbulent flow is at a Reynolds Number of 2000 .

7) The frictional pressure drop (major head loss) must be included in each axial control volume and should be based on the control volume average conditions. The internal pipe support pressure drop coefficients (minor head loss) are based on the full pipe flow area and are applied in the control volume downstream of the hardware location. The density, velocity, and friction factor in the minor head loss term are based on control volume averages.

8) The heat added to the flow inside a control volume is based on the average heat flux of the APS (based on the heat at the beginning and ending locations for the control volume).

\section{Problem Specific Input}

Table 2 contains the inputs for the vertical heated pipe. Figure 1 contains the various APSs (heat flux as a function of the normalized pipe length), with each student assigned one of the nine axial power shapes. Each of the Figure 1 APSs is based on a peak-toaverage heat flux of 1.7 and is peaked at a different location along the heated pipe length. Each APS in Figure 1 integrates axially to the average heat flux defined in Table 2.

Table 2 - Vertical heated pipe conditions.

\begin{tabular}{|c|c||c|c|}
\hline Pipe characteristic & Value, units & Pipe characteristic & Value, units \\
\hline Pipe inside diameter & 1.0 inch & $\begin{array}{c}\text { Vertical pipe length (all } \\
\text { heated) }\end{array}$ & $12 \mathrm{feet}$ \\
\hline $\begin{array}{c}\text { Pipe inner surface } \\
\text { roughness }\end{array}$ & $7.5 \mathrm{E}-5$ inches & $\begin{array}{c}\text { Internal pipe support } \\
\text { locations }\end{array}$ & $\begin{array}{c}3,6 \text {, and } 9 \text { feet } \\
\text { from start of } \\
\text { pipe }\end{array}$ \\
\hline \multicolumn{4}{|c|}{ Pipe boundary conditions } \\
\hline Inlet temperature & $550^{\circ} \mathrm{F}$ & Average heat flux & $\begin{array}{c}0.25 \mathrm{MBtu} /(\mathrm{hr}- \\
\left.\mathrm{ft}^{2}\right)\end{array}$ \\
\hline Mass velocity & $\begin{array}{c}1.0 \mathrm{Mlb}_{\mathrm{m}} /(\mathrm{hr}- \\
\left.\mathrm{ft}^{2}\right)\end{array}$ & $\begin{array}{c}\text { Pipe exit pressure (used } \\
\text { to evaluate all thermal } \\
\text { properties) }\end{array}$ & $2250 \mathrm{psia}$ \\
\hline Local heat flux & $\begin{array}{c}\text { Varies axially } \\
\text { (see Figure 1) }\end{array}$ & & \\
\hline
\end{tabular}




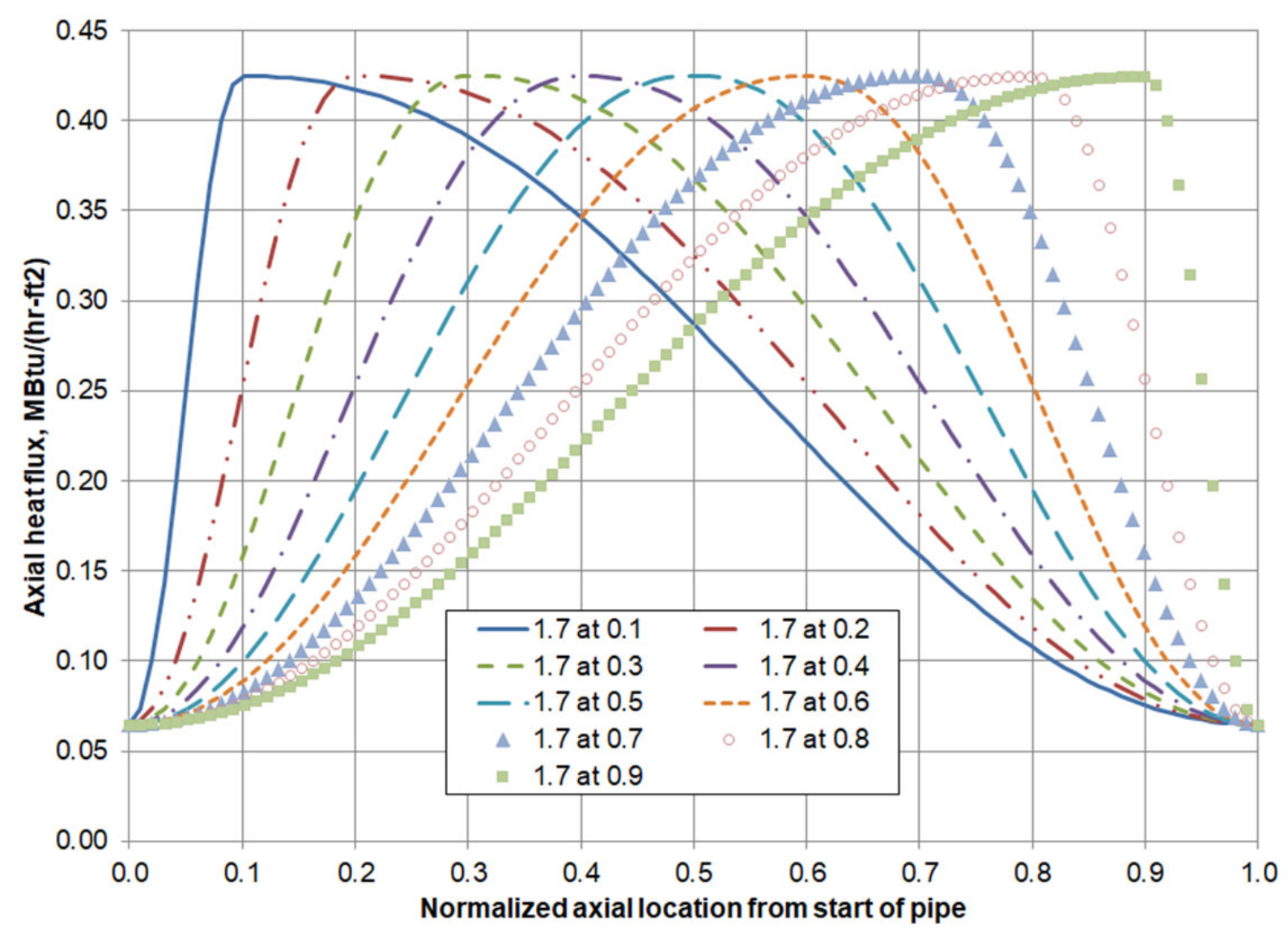

Figure 1 - APS as a function of normalized axial location in the vertical pipe.

The internal pipe supports at 3,6, and 9 feet are Reynolds Number dependent and are applied only over the length of the control volume downstream of the pipe support location. The form of the minor loss coefficients are as follows:

$$
\begin{aligned}
& K_{L}=a(R e)^{b}+c \\
& 3 \text { foot location } \rightarrow a=125, b=-0.5, c=2.0 \\
& 6 \text { foot location } \rightarrow a=150, b=-0.4, c=3.0 \\
& 9 \text { foot location } \rightarrow a=200, b=-0.6, c=4.0
\end{aligned}
$$

\section{Results}

The goal of the project is to determine if the pipe is operating at safe conditions (safety factor in Equation 7 is greater than 1.0 along the entire length of the pipe). In an industrial application the minimum allowable safety factor would account for experimental variations and would base the safety factor on a numerical value higher than 1.0. The minimum safety factor considered to be acceptable for an industrial application of Equations 7 and 8 is $1.32^{4}$. 
Each of the nine APSs in Figure 1 produce different axial results, although the same exit conditions exist for temperature, enthalpy, pipe inner surface temperature, and uniform CHF (Equation 8) are identical. The exit results for the previously mentioned parameters are identical since the APSs all integrate to the same average axial heat flux.

The following figures contain the results of the MATLAB ${ }^{\circledR}$ calculations as a function of axial location relative to the pipe inlet for the boundary conditions in Table 2 for each of the nine Figure 1 APSs:

- Figure 2 - Enthalpy.

- Figure 3 - Pipe inner surface temperature.

- Figure 4 - Pressure drop (from the pipe inlet).

- Figure 5-Safety factor. The safety factor is also called the departure from nucleate boiling ratio (DNBR).

The results in Figures 2 through 5 are based on 48 uniform axial control volumes of 3inches in length. The legend in each figure defines the peak-to-average heat flux (1.7) and the location of the peak.

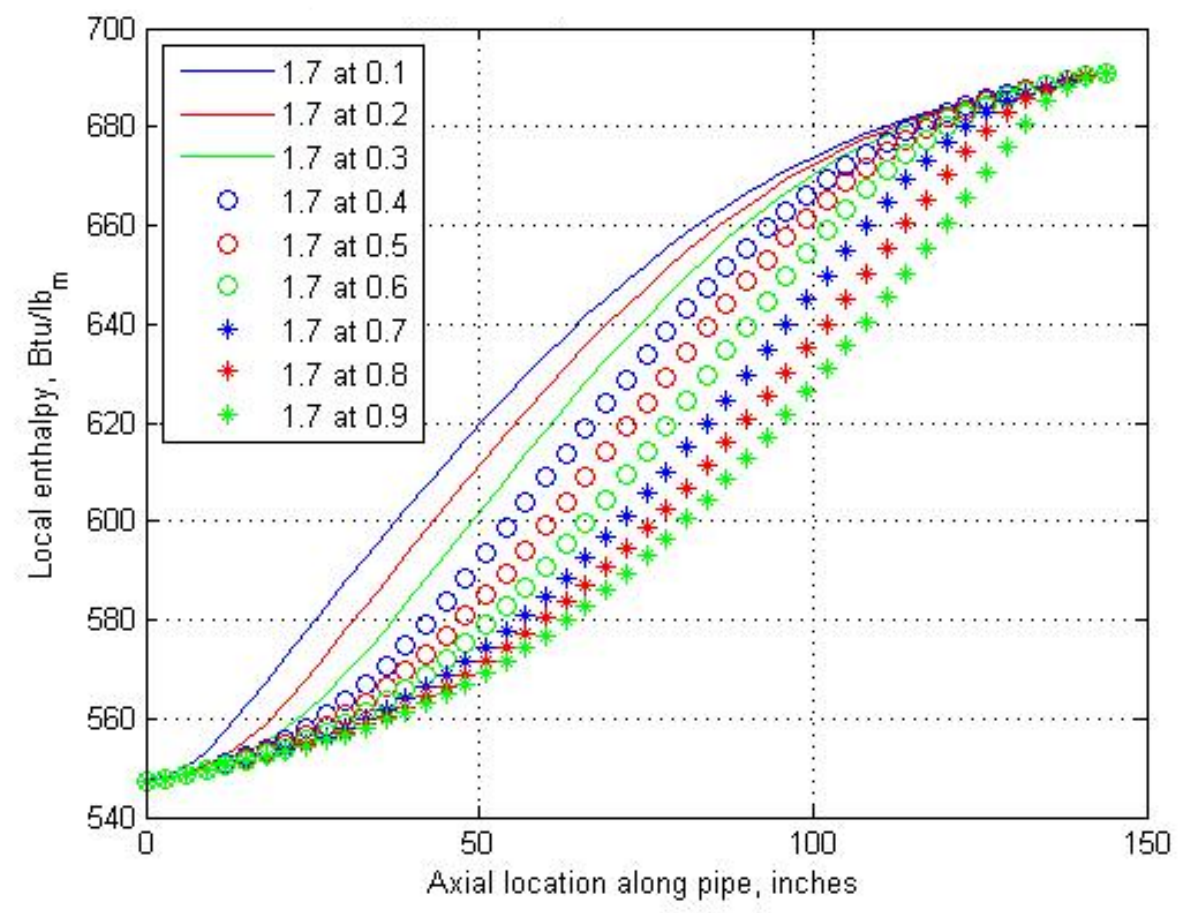

Figure 2 - Enthalpy as a function of axial location relative to the pipe inlet. 


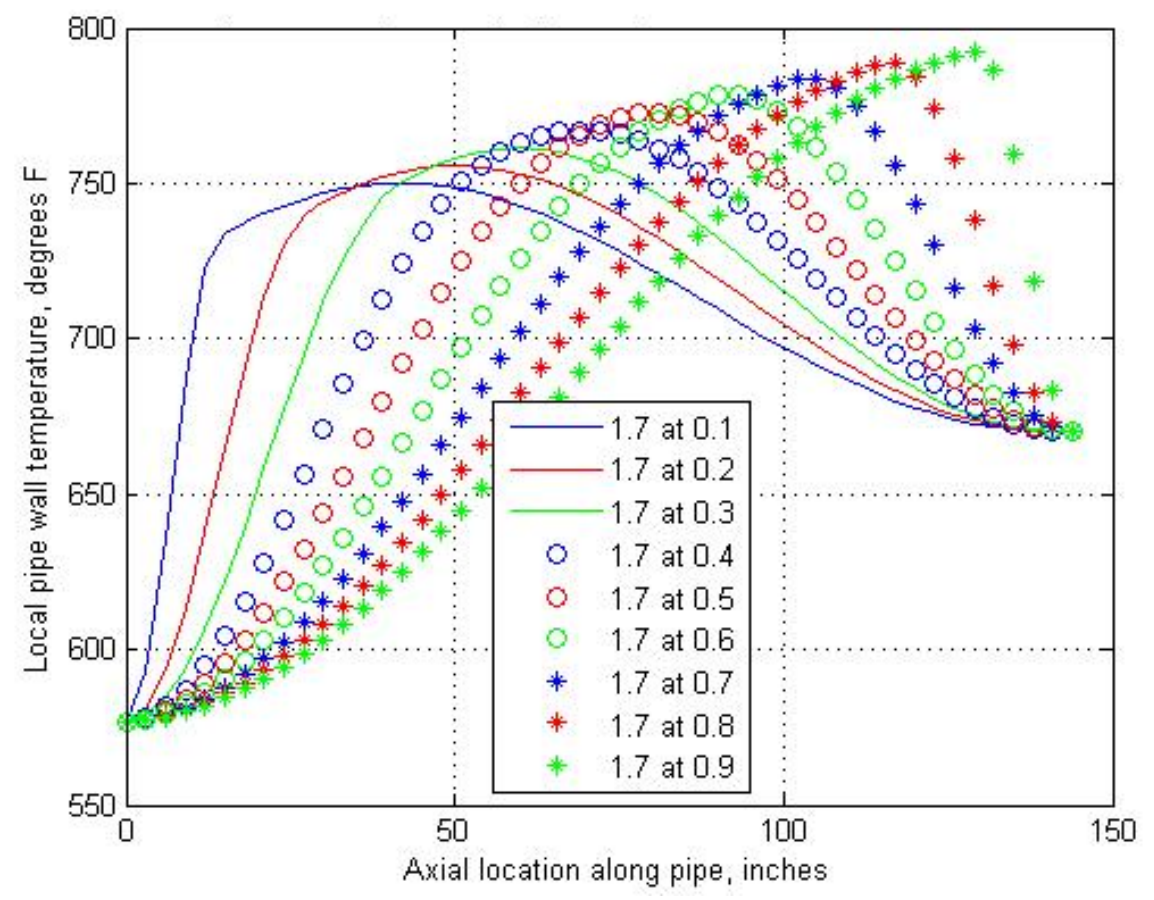

Figure 3 - Pipe inner surface temperature as a function of axial location relative to the pipe inlet.

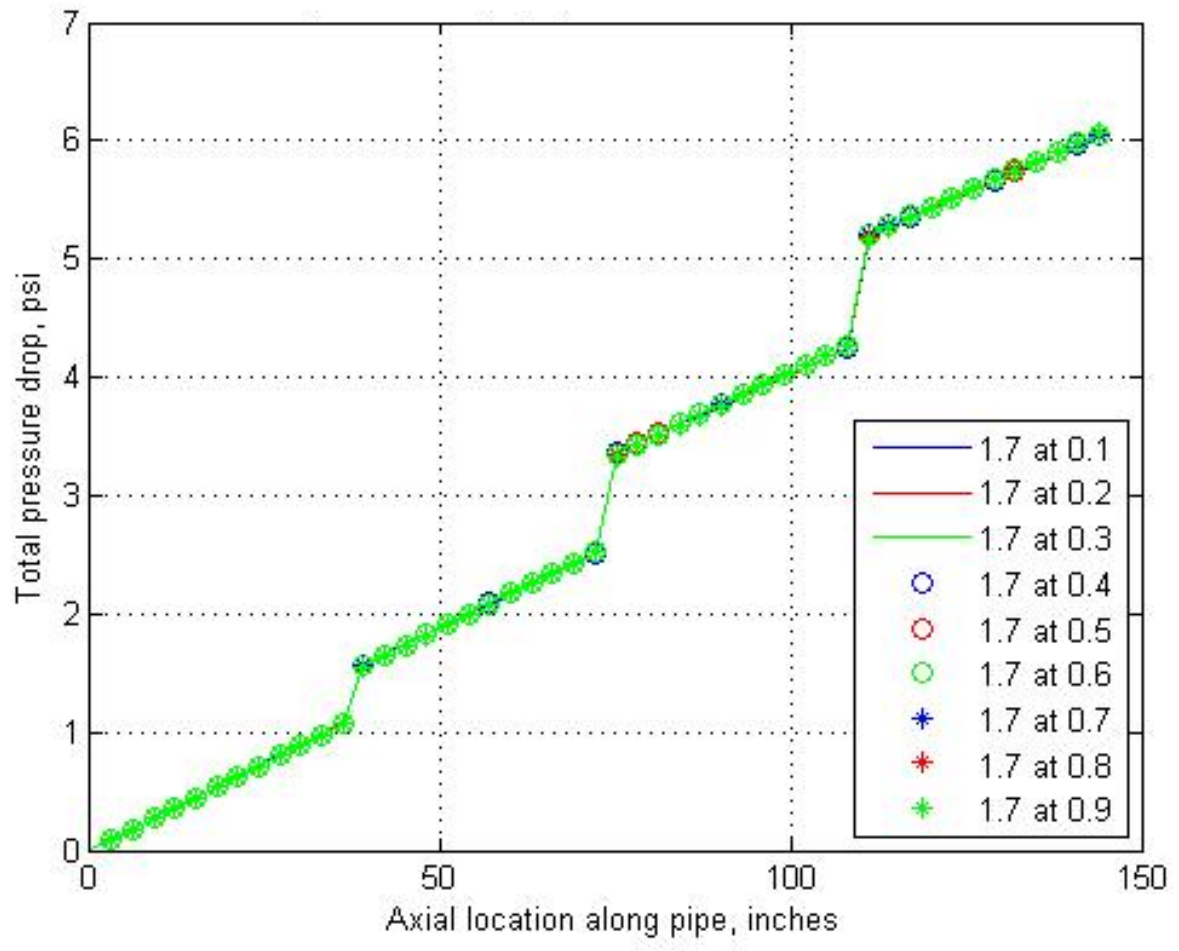

Figure 4 - Pressure drop (from the pipe inlet) as a function of axial location relative to the pipe inlet. 


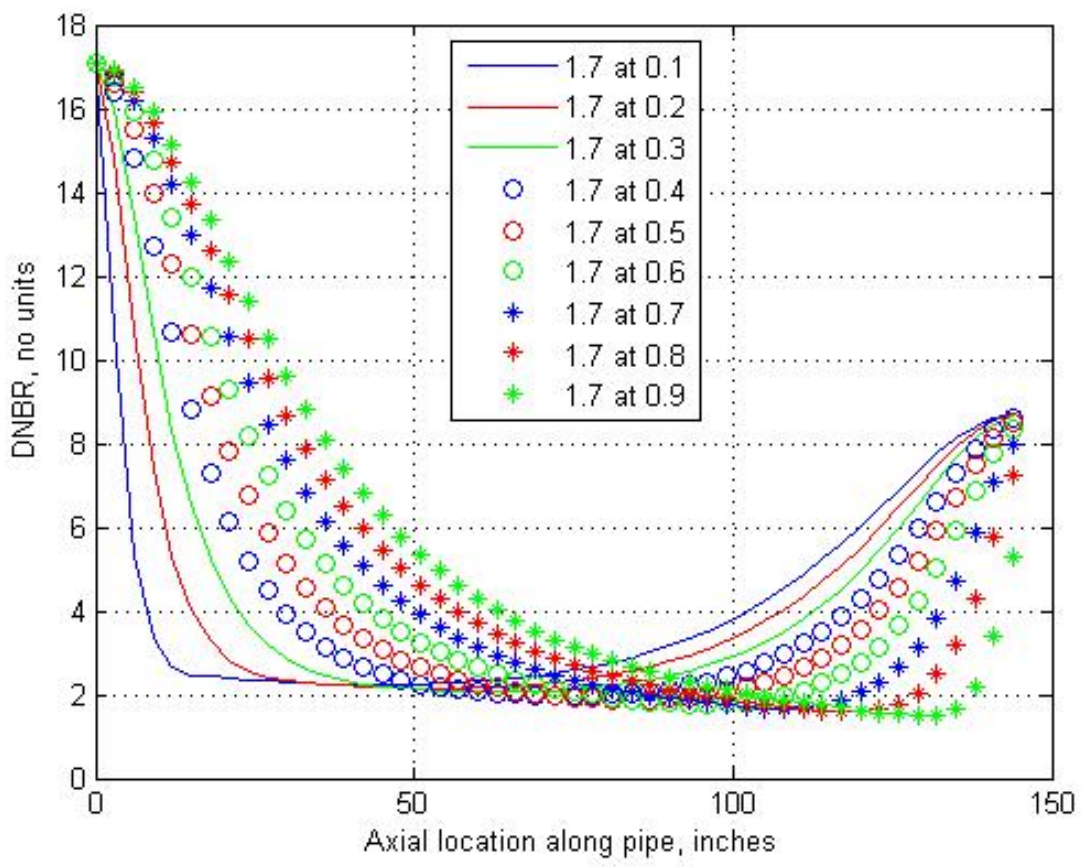

Figure 5 - Safety factor as a function of axial location relative to the pipe inlet.

The minimum safety factors, which determine if the design operates safely, range from 2.24 at 45 inches for the 1.7 at 0.1 APS to 1.48 at 129 inches for 1.7 at 0.9 APS. The pipe operating conditions are within a safe range for all the APSs. The minimum safety factor moves closer to the end of the pipe where fluid temperatures/enthalpies are higher as the peak power location moves higher in the pipe.

Upon completion of the MATLAB ${ }^{\circledR}$ calculations the students are required to generate an engineering project report that contains the project introduction, derivation of governing equations (based on starting with the standard textbook equations), units checks, coding description (including flow charts), results, verification of implemented equations, and final conclusions. These are the type of topics typically included in an engineering analysis report in industry. The report must include graphical representations of the results and a final recommendation as to whether the design (based on the nonuniform axial power shape) is safe.

The students are required to perform verifications of all the implemented equations. The verifications require the students to perform hand calculations on various MATLAB ${ }^{\circledR}$ generated results. The instructors performed the same type of verifications using hand calculations and EXCEL ${ }^{\circledR}$-based VBA coding.

\section{Learning Assessment}

The vertical pipe flow problem is assigned during a junior-level heat transfer class. The same semester the students take heat transfer they also are taking fluid dynamics, and a 
computer-aided engineering course. The students completed a first course in thermodynamics the previous academic year.

To evaluate the effect of the vertical pipe flow problem in terms of improving the students' understanding of thermal science as an integrated discipline, a learning assessment was performed several weeks into the heat transfer class. Within the first few weeks of the heat transfer class, the students have encountered the basics of heat transfer, were provided a detailed description of the project, and were shown a video of a waterbased experiment demonstrating the importance of an understanding CHF. The video showed the transition of the flow channel from subcooled nucleate boiling to the point of $\mathrm{CHF}$ where the heated surface fails due to the rapid change in surface temperatures, due to the decreased heat transfer. The learning assessment is a 10-question, multiple-choice questionnaire and is contained in the Appendix.

Figure 6 contains the fraction of students in the class (two sections with a total of 39 students) with the correct responses to the learning assessment as a function of the Appendix question number. Both the pre- and post-course assessment results are included in Figure 6. Question 5 dealt with identifying the equations used in the project, which are identified in the Problem Formulation section. Question 5 is a multi-part question that had no students providing all the correct responses in both the pre- and postproject learning assessments. Question 10 dealt with the real-world application of the equations defined in the Problem Formulation section. The low correct response rate indicates the students did not see the real-world applications, even though they were stressed throughout the semester. The student verbal responses to the learning assessment questions were not meaningful as they indicated the students were guessing. The students who did respond correctly to Question 6, which deals with reasoning through the axial change in the pipe, indicated the students could rationalize the correct behavior. 


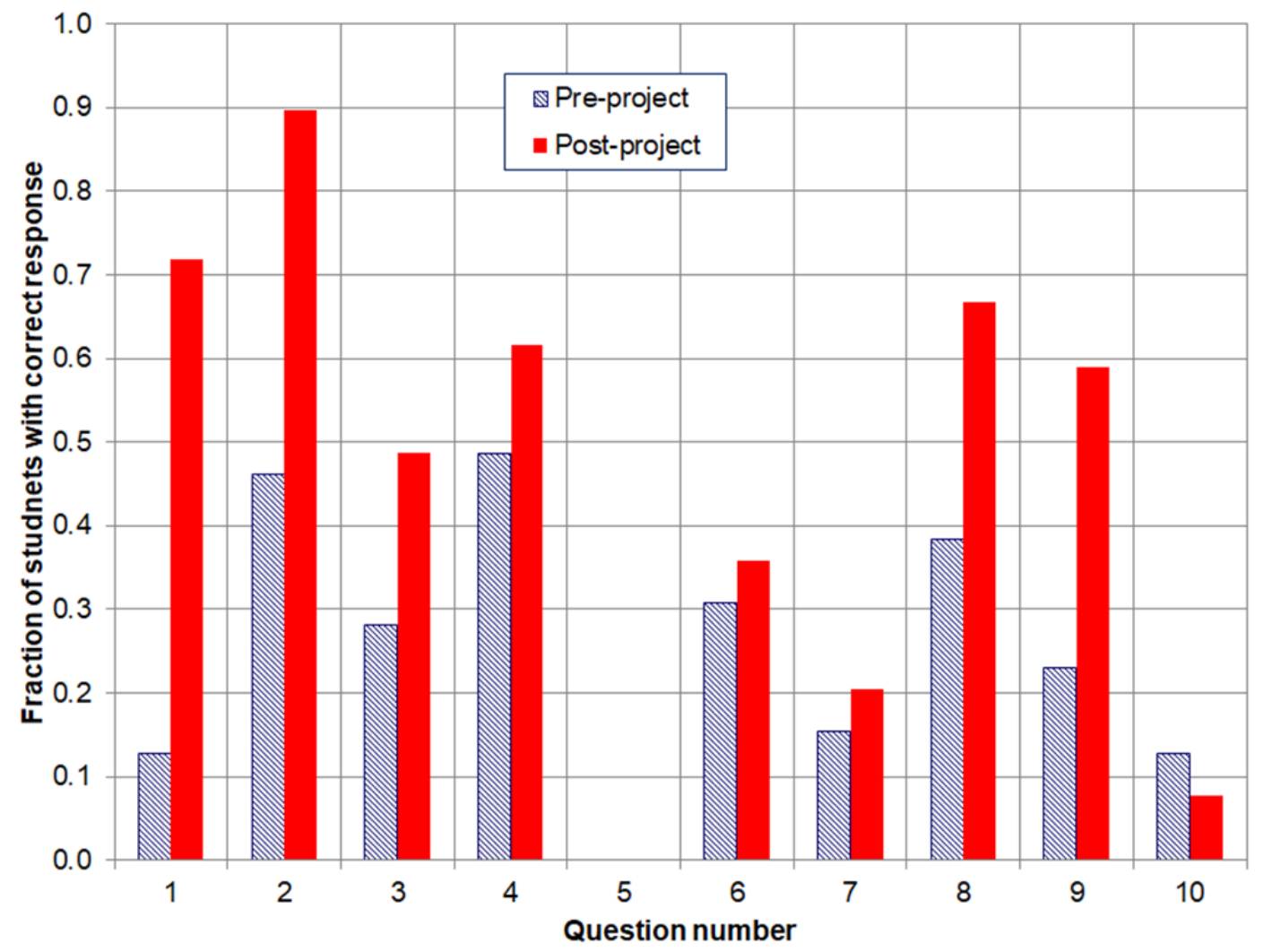

Figure 6 - Fraction of all students with the correct questionnaire response as a function of the Appendix question number.

There was an overall increase in the students' awareness of four of the primary equations used in the pipe flow analysis (first law of thermodynamics, mechanical energy equation, Newton's law of cooling, and safety factor (CHF)), based on the responses to Questions 1 through 4 and Question 8. The understanding of the use of an EOS and how it influences and couples the thermal science equations was not improved, based on the response to Question 5, which had several correct responses. Approximately half the students provided at least one correct response for both the pre- and post-project questionnaire for Question 5. In future courses using this MATLAB ${ }^{\circledR}$ project, additional emphasis must be placed on the integration of the equations through the EOS to improve the students' perception of thermal science as an integrated discipline.

\section{Conclusions}

The heated pipe flow problem is a simplified version of an industrial heat flux controlled system where maintaining safe operating margins is required. In addition to evaluating safety margins it is also important to understand the forced flow requirements of the system by obtaining the overall pressure drops. An integrated thermal science problem based on the first law of thermodynamics, Newton's law of cooling, mechanical energy equation, and a critical heat flux correlation is used to determine safe operating margins and provide a pressure drop. These equations are all linked using an equation of state. 
The heated pipe flow problem is solved using MATLAB ${ }^{\circledR}$, with a range of different axial power shapes assigned to the students.

The learning assessments indicated the problem increased the students' understanding of the four basic equations, but additional instructional activities are required to enhance overall understanding of thermal science as an integrated discipline. Some of these additional activities include performing limited hand calculations using an integrated set of equations.

In the future an expanded boiling curve, at least through saturated nucleate boiling, inclusion of two-phase flow conditions based on an open-literature subcooled and bulk boiling void fraction model, and optimization of boundary/inlet conditions (Table 2) to obtain safety factor targets are being considered. These additional features would be based on standard industrial models.

\section{Nomenclature}

a, $A_{1}$ through $A_{9} \quad$ Coefficients for the uniform CHF correlation

APS Axial power shape

$\mathrm{A}_{\mathrm{ht}} \quad$ Heat transfer area

$\mathrm{C} \quad$ Coefficient for the nonuniform $\mathrm{F}_{\mathrm{D}}$ term

CHF Critical heat flux

D Hydraulic diameter of pipe

DNBR Departure from nucleate boiling ratio

e Control volume exit (subscript)

$\mathrm{E}_{\mathrm{CV}} \quad$ Control volume energy (in transient term)

EOS Equation of state

$\mathrm{f} \quad$ Friction factor

$\mathrm{F}_{\mathrm{D}} \quad$ Nonuniform factor for the CHF correlation

g Acceleration due to gravity

G Mass flux

h Enthalpy

$\mathrm{h}_{\text {conv }}$

$\mathrm{h}_{\mathrm{f}}$

$\mathrm{h}_{\mathrm{fg}}$

$\mathrm{h}_{\text {Pump }}, \mathrm{h}_{\text {Turbine }}$

Heat transfer coefficient

Saturated liquid enthalpy

Latent heat of vaporization

Head loss due to pumps and turbine (not used in this problem)

Control volume inlet (subscript)

IAPWS-IF97 International Association for the Properties of Water and SteamIndustrial Formulation 1997

k Thermal conductivity

$\mathrm{K}_{\mathrm{L}} \quad$ Minor head loss coefficient

L Axial location in pipe

$\dot{m} \quad$ Mass flow rate

$\mathrm{p} \quad$ Pressure

Pr Prandtl Number

$\dot{Q}_{c v} \quad$ Heat rate 


$\begin{array}{cl}q_{C H F}^{\prime \prime} & \text { Uniform critical heat flux } \\ \text { Re } & \text { Reynolds Number } \\ \text { TWall, }_{\text {Fluid }} & \text { Wall (pipe inner surface) and fluid temperatures } \\ \mathrm{V} & \text { Velocity } \\ \text { VBA } & \text { Visual basic for Applications (EXCE }{ }^{\circledR} \text {-based coding) } \\ \dot{W}_{c v} & \text { Control volume work } \\ \mathrm{x}_{\mathrm{CHF}} & \text { Thermodynamic quality for the CHF correlation } \\ \mathrm{z} & \text { Axial elevation }\end{array}$

\section{Bibliography}

[1] Y. Cengel and M. Boles, Thermodynamics: An Engineering Approach, $8^{\text {th }}$ Edition, New York, New York, McGraw Hill Education, 2015.

[2] R. Hibbeler, Fluid Mechanics, Prentice Hall, Pearson, 2014.

[3] Y.Cengel, A. Ghajar, Heat and Mass Transfer: Fundamentals and Applications, $5^{\text {th }}$ Edition, New York, New York, McGraw Hill Education, New York, 2015.

[4] Correlation of Critical Heat Flux in a Bundle Cooled by Pressurized Water, BAW10000A, Lynchburg, Virginia, Babcock \& Wilcox, 1976.

[5] M. Mikofski, IAPWS_IF97, https://github.com/mikofski/IAPWS_IF97. Obtained from https://www.mathworks.com/matlabcentral/fileexchange/35710-iapws-if97functional-form-with-no-slip. Accessed August 31, 2017.

[6] D. Rowe, COBRA-IIIC: A Digital Computer Program for Steady State and Transient Thermal-Hydraulic Analysis of Rod Bundle Nuclear Fuel Elements, BNWL-1695, Richland, Washington, Battelle Pacific Northwest Laboratories, 1973.

\section{Appendix - Learning Assessment}

This is a multiple choice assessment. The questions and potential responses provided to the students are as follows:

1) What is the basis of the fluid energy equation used in the heated pipe flow problem? Which of your thermal science courses provided the fluid energy equation?

a) Mechanical energy equation.

b) First law of thermodynamics.

c) Second law of thermodynamics.

d) Equation of state.

e) Newton's law of cooling.

f) Fourier's conduction law.

g) Critical heat flux empirical correlation.

State why you selected the response you did. 
2) What is the basis of the pressure drop equation used in the heated pipe flow problem?

a) Mechanical energy equation.

b) First law of thermodynamics.

c) Second law of thermodynamics.

d) Equation of state.

e) Newton's law of cooling.

f) Fourier's conduction law.

g) Critical heat flux empirical correlation.

State why you selected the response you did.

3) What is the basis of the temperatures on the pipe wall used in the heated pipe flow problem?

a) Mechanical energy equation.

b) First law of thermodynamics.

c) Second law of thermodynamics.

d) Equation of state.

e) Newton's law of cooling.

f) Fourier's conduction law.

g) Critical heat flux empirical correlation.

State why you selected the response you did.

4) What is the basis of the safety factor used in the heated pipe flow problem?

a) Mechanical energy equation.

b) First law of thermodynamics.

c) Second law of thermodynamics.

d) Equation of state.

e) Newton's law of cooling.

f) Fourier's conduction law.

g) Critical heat flux empirical correlation.

State why you selected the response you did.

5) Which of the following equations used in the heated pipe flow problem require the equation of state? Identify all equations that apply to this problem.

a) Mechanical energy equation.

b) First law of thermodynamics.

c) Second law of thermodynamics.

d) Equation of state.

e) Newton's law of cooling.

f) Fourier's conduction law.

g) Critical heat flux empirical correlation.

h) None of the above.

i) All of the above.

State why you selected the response you did. 
6) As the water flows up the vertical heated pipe which of the following occurs?

a) Fluid temperature increases, pressure drop decreases, pipe wall temperature decreases, and safety factor increases.

b) Fluid temperature decreases, pressure drop decreases, pipe wall temperature increases, and there is no impact on the safety factor.

c) Fluid temperature increases, pressure drop increases, pipe wall temperature increases, and safety factor decreases.

d) Fluid temperature increases, pressure drop increases, pipe wall temperature increases, and safety factor increases.

e) None of the above.

State why you selected the response you did.

7) What is analogous to violating the safety factor, based on boiling a pot of water on the stove?

a) Water heats up and starts boiling but the steam bubbles are attached to the surface of the pot.

b) Water heats up and the steam bubbles are injected into the water that is not boiling.

c) Water heats up and a water/steam mixture overflows the top of the pot.

d) The water evaporates and there is no water left in the pot.

e) There is no analogy.

State why you selected the response you did.

8) What is the difference between major and minor head losses? Which equation do they apply to?

a) Major head losses are the most important pressure drops. Minor head losses are the least important pressure drops. The two head loss terms apply to the first law of thermodynamics.

b) Major head losses are the most important pressure drops. Minor head losses are the least important pressure drops. The two head loss terms apply to the mechanical energy equations.

c) Major head losses are the pressure losses associated with friction on the pipe wall. Minor head losses are the pressure losses due to flow geometry or hardware. The two head loss terms apply to the first law of thermodynamics.

d) Major head losses are the pressure losses associated with friction on the pipe wall. Minor head losses are the pressure losses due to flow geometry or hardware. The two head loss terms apply to the mechanical energy equation.

e) Major and minor losses have no application in the pipe flow problem. State why you selected the response you did

9) Do you anticipate the pipe flow to be turbulent or laminar?

a) The flow is laminar because almost all flows of engineering interest are laminar. 
b) The flow is turbulent because almost all flows involving heat transfer are turbulent.

c) The flow is laminar because the pipe wall is expected to be very smooth.

d) The flow is turbulent because the pipe Reynolds number is expected to well exceed 2000.

State why you selected the response you did.

10) How does this project relate to a real-world thermal science application?

a) There are no real-world applications of this project.

b) I have no idea.

c) Water flowing inside the cooling system of my car.

d) Water flowing through a hydroelectric dam as part of the electrical grid.

e) It applies to all thermal science real-world applications.

f) Heat flux controlled system.

State why you selected the response you did. 